\title{
LA MARCHA INDIGENA DEL "TIPNIS" EN BOLIVIA Y SU RELACIÓN CON LOS MODELOS EXTRACTIVOS DE AMERICA DEL SUR
}

\author{
SARELA PAZ ${ }^{1}$
}

Iniciando la década del 2000, en Cochabamba, la tercera ciudad de Bolivia, se desencadenó una movilización espontánea realizada por los habitantes de la ciudad y sus regiones aledañas, movilización producida ante el intento del gobierno de Sánchez de Lozada de concesionar las aguas de la cordillera que abastecen al valle interandino que cobija la mencionada ciudad a una transnacional. Dicho episodio conocido como la Guerra del Agua, abrió un ciclo de movilizaciones populares en Bolivia orientadas claramente a pensar cómo es posible desmantelar el armazón institucional neoliberal que logró la capitalización y transnacionalización de varios recursos naturales estratégicos en Bolivia (petróleo/gas/minería). La década del 2000, saturada de contradicciones y luchas internas en política boliviana, logró episodios de gran alance que permitieron discutir al ciudadano boliviano el futuro de recursos naturales estratégicos como gas y petróleo, agua y recursos mineralógicos. Movilizaciones y desobediencia civil marcaron el debate. Industrialización, desarrollo productivo que atienda necesidades de la población, salidas económicas más allá del capitalismo, nos hicieron pensar a los bolivianos en la posibilidad de un horizonte distinto al que habíamos ocupado secularmente en términos de la economía global. Además, el advenimiento de un presidente indígena en diciembre del 2005, inédito en la historia nacional, nos invitó a considerar

\footnotetext{
${ }^{1}$ Doutora em Antropología, professora de pós-graduação em universdidades bolivianas e pesquisadora sobre temas referentes a territórios indígenas, recursos naturais, interculturalidade e gestão política do território. Trabalhou em diversas ocasiões no Território Indígena e Parque Nacional Isiboro Sécure (TIPNIS), coordenou o primeiro plano de manejo para a área nos anos 1992-1993 (CIDDEBENI). Tomou parte na equipe de Avaliação Ambiental Estratégia dos TIPNIS em 2011. A pesquisa mais importante que realizou na área se refere a entender como a chegada dos produtores de folha de coca modificou a vida das comunidades indígenas num trabalho denominado Hombres de río, hombres de camino: relaciones interétnicas en las nacientes del río Mamoré (UMSS, 1991).
} 
seriamente las posibilidades de un cambio profundo y estructural en la sociedad boliviana.

Una década después se produjo la marcha indígena del TIPNIS, en los meses de agosto, septiembre y octubre del 2011. Dicha marcha mostró los caminos y senderos transitados en relación a los posibles sueños y horizontes de cambio que nos habíamos propuesto los bolivianos en la primera mitad del siglo XXI. La primera contradicción/constatación que nos mostro la mencionada marcha fue los intereses disímiles entre los pueblos indígenas respecto a cómo entender el desarrollo, la segunda contradicción/constatación que develó la marcha fue que el horizonte económico de modelo extractivo primario exportador no sólo que no había cambiado sino que se había ahondado durante la década en que los bolivianos expectábamos avanzar hacia la industrialización de los hidrocarburos, para convertirnos en algo más que un país que ofrece materias primas en el mercado global. La tercera contradicción/constatación que mostro la marcha indígena es que la dimensión política de Estado Plurinacional presenta enormes contradicciones con un modelo extractivo primario exportador, modelo que requiere para sus operaciones productivas fundamentos y bases de un Estado centralista y mono nacionalista. ¿La forma política del Estado Plurinacional puede operar bajo un modelo extractivo en la economía? ¿Es posible que los intereses del modelo extractivo primario exportador puedan coincidir con los intereses de los pueblos indígenas?.

El presente artículo se propone analizar el conflicto acaecido con la marcha indígena del TIPNIS en el 2011, reflexionando acerca de cómo dicha movilización muestra las paradojas que inscriben al Estado Plurinacional de Bolivia, Estado que se plantea funcionar con principios económicos y políticos plurales que quedan limitados por el horizonte de un modelo económico extractivista que hegemoniza las políticas de Estado. Ciertamente, el desafío es poder explicar la relación entre la movilización indígena del TIPNIS y la dimensión del modelo extractivista en Bolivia, lo cual supone describir las características del conflicto, los actores que están inmersos, la relación entre los actores, sus intereses, y los intereses que se ponen en juego cuando el Estado busca expandir un modelo extractivista primario exportador. En la indagación de las mencionadas variables es importante reparar en los proyectos de desarrollo que empujaron las comunidades indígenas del TIPNIS, observando cómo ellos son una salida distinta a la propuesta extractiva que domina las razones de Estado. Con dichas ideas, trazaré algunas conclusiones explicativas de lo que está aconteciendo en relación a las distintas visiones de desarrollo que nos 
proponen los pueblos indígenas en Bolivia y el rol que está jugando el Estado en relación a esas visiones.

\section{Algunos antecedentes sobre el TIPNIS}

El TIPNIS es un Parque Nacional y Territorio Indígena; esto es, un territorio que por razones de la historia posee una doble condición: ser área protegida y a la vez ser territorio indígena. Como área protegida opera desde el año 1965, mediante el Decreto Ley \# 07401 que fue promulgado por el gobierno de René Barrientos Ortuño. Muchos se preguntaran cómo es que fue decretado un Parque Nacional en aquellos años cuando la política pública de la época se caracterizaba por un nacional populismo producto de la revolución agraria de 1952 y la ocupación -colonizaciónde tierras amazónicas en Bolivia. En realidad, los entretelones de la historia nos muestran a dos personas ligadas a los pueblos indígenas que habitaban en el TIPNIS, un explorador habitante del antiguo Pueblo de Todo Santos (río Chapare) Hans Hoffman y un misionero jesuita llamado padre Erik, ambos mantenían vínculos culturales y religiosos con las comunidades indígenas de la zona y coincidieron en la necesidad de que el Estado delimite un lugar de refugio para las comunidades indígenas amazónicas, puesto que la colonización proyectada en los años 50 y 60 en la zona del Chapare, implicaba la ocupación de territorio de los pueblos indígenas amazónicos.

¿Por qué el Estado boliviano ocupaba tierras de los pueblos amazónicos?. En la lectura constitucional profundamente nacionalista de la época, las tierras de las tribus selvícolas en realidad formaban parte de lo que se consideraba tierra fiscal; es decir, tierra de dominio y propiedad del Estado. Así, éste podía decidir acerca de su destino. Uno de los grandes proyectos estatales implementados después de la revolución de 1952 fue justamente la marcha hacia el oriente boliviano (SORUCO, 2008), la ocupación de tierras en los llanos amazónicos y chaqueños de Bolivia que buscaba consolidar una agroindustria exportadora en la región de Santa Cruz (caña, algodón, girasol, soya) y, a su vez, implementar planes y programas de colonización a la región de los yungas por parte de sectores campesinos andinos ya que éstos iban a verse expuestos rápidamente a un proceso de parcelación y empobrecimiento de su economía campesina (LASERNA, 1987). El contingente de campesinos colonizadores a los yungas bolivianos estuvo conformado por quechuas y aymaras que buscaron expandir sus iniciativas agrarias en tierras bajas y el Chapare se convirtió en uno de los lugares de destino. Proyectos camineros como el 1 
y 4 programados en la primera mitad de la década del 60 que comunicaban Villa Tunari con Puerto Villarroel y apoyados por USAID, nos muestran ya un programa de penetración caminera al TIPNIS (Ver mapa Ministerio de Economía Nacional 1966) ${ }^{2}$. Esta es una razón fundamental para que las personas arriba mencionadas hayan gestionado la creación del Parque Nacional como un territorio destinado al refugio de las tribus selvícolas.

El TIPNIS como territorio indígena ha sido creado en 1990 mediante Decreto Supremo \# 22619 en la gestión del presidente Jaime Paz Zamora. La aceptación de dicho territorio tiene que ver con la primera marcha indígena de tierras bajas en agosto septiembre de 1990. Las comunidades indígenas del TIPNIS, junto con comunidades indígenas de Bosque de Chimanes y comunidades indígenas del pueblo siriono, desarrollaron su demanda de reconocimiento al territorio indígena mediante el mecanismo de la marcha. Fruto de la movilización de los años 90 y la aceptación de la figura jurídica de territorio indígena, el Estado boliviano acepta suscribir el Convenio 169 de la OIT que protege los derechos de los pueblos indígenas y tribales, desarrollando una reforma constitucional donde se introduce la figura de territorio indígena bajo el nombre de Tierra Comunitaria de Origen (TCO), figura de propiedad colectiva sobre la tierra que es reconocida a favor de los pueblos indígenas en la Ley INRA promulgada en 1996. A partir de entonces el TIPNIS es un territorio indígena legalmente constituido (reconocido por el Estado) en beneficio de tres pueblos indígenas amazónicos: los yuracares y chimanes que son pueblos que habitan la selva alta y desarrollan una economía étnica amazónica basada en una relación compleja entre caza, pesca, recolección y agricultura y el pueblo mojeño trinitario que tiene como centro territorial las regiones de bosques y sabanas inundables y que también forma parte de la economía étnica amazónica.

El epicentro del conflicto del TIPNIS y la marcha indígena del 2011 surge por un hecho relativo a los derechos territoriales que los pueblos yuracarés, chimanes y moxeño trinitarios tienen; esto es, el derecho propietario de su territorio que les faculta a ser consultados cuando una medida del Estado les afecte. El gobierno boliviano de Evo Morales

\footnotetext{
${ }^{2}$ Mapa elaborado por el Ministerio de la Economía Nacional de Bolivia con apoyo de U.S. Agency for International Development, Proyectos Viales 1 y 4 . El proyecto 1 suponía la comunicación Villa Tunari - Puerto Villarroel con $85.970 \mathrm{~km}$, el proyecto 4 suponía Cochabamba - Villa Tunari con $156.132 \mathrm{~km}$. El mismo proyecto 4 suponía Villa Tunari - río Isiboro con $43.719 \mathrm{~km}$. Dicha iniciativa apoyada por U.S. Agency for International Development fue licitada el 5 de mayo de 1966 con enmiendas fechadas al 5 de julio de 1966. Ver mapa 1.
} 
decidió hacer una carretera que atraviese el territorio indígena del TIPNIS y que comunique dos centros urbanos intermedios como son Villa Tunari y San Ignacio de Moxos ${ }^{3}$. El proyecto carretero fue aprobado por el gobierno de Evo Morales en el año 2007 sin una negociación o Consulta Previa con los pueblos del territorio en cuestión. A partir de ello se desencadeno un conjunto de hechos que deterioraron profundamente la relación del Poder Ejecutivo con la dirigencia indígena amazónica y fue en el mes de abril del 2011 que la Asamblea Legislativa Plurinacional aprobó el crédito que otorgaba BNDES ${ }^{4}$ para la construcción de la carretera, lo que devenía en el ingreso de la maquinaria de obras a la región inicial del Parque (poblado de Isinuta). En ese contexto los dirigentes indígenas del TIPNIS convocaron a un encuentro territorial, que se constituye la máxima instancia de decisión interna, en la comunidad de San Pablo del Isiboro y sacaron un voto resolutivo que dice claramente que los pueblos indígenas del TIPNIS no se oponen a la carretera Villa Tunari San Ignacio de Moxos sino que se oponen a que dicha carretera pase por el centro del territorio y lo parta en dos.

Considerando los elementos expuestos, uno podría creer que se trata expresamente de un conflicto entre el gobierno y las comunidades indígenas del TIPNIS. No obstante, acercándonos a las lógicas productivas del territorio lo que encontramos, en primera instancia, son dos lógicas productivas que nos muestran dos modelos de desarrollo vinculados a actores sociales diferentes y dinámicas económicas de distinta escala y, en segunda instancia, las iniciativas de un Estado que nos propone la construcción de un camino como parte de una propuesta de desarrollo interdepartamental pero sin hablarnos claramente de los vínculos que hay entre sectores que componen las articulaciones de poder dentro del gobierno de Evo Morales y los modelos de desarrollo que se desenvuelven en el TIPNIS, menos aún de cómo la carretera en cuestión forma parte los planes de explotación petrolera que tiene el gobierno boliviano y los planes de desarrollo de infraestructura que están liderizados por el Brasil a través del plan Iniciativa de Integración Regional Sudamericana (IIRSA).

\footnotetext{
${ }^{3}$ Un balance sobre el Derecho a la Consulta y los procedimientos institucionales que contempla la Constitución boliviana encontraremos en el artículo escrito por Sarela Paz, "El conflicto del Territorio Indígena Parque Nacional Isiboro Sécure (TIPNIS): sus consecuencias para el Estado Plurinacional de Bolivia", en Estado Plurinacional: balances y perspectivas, La Paz, PNUD-Embajada de Suecia, boletín \# 3 y 4, enero, 2012.

${ }^{4}$ Banco Nacional de Desarrollo Económico y Social del Brasil que invierte en iniciativas de infraestructura y extracción. En el campo económico suele actuar con la figura de sociedad mixta público/privado en coordinación con Banco do Brasil.
} 


\section{Lógicas de desarrollo y pueblos indígenas}

¿Cuáles son las dos lógicas productivas y de desarrollo que se han puesto en juego en el conflicto del TIPNIS y que forman parte de los actores que viven dentro de él? Retomando el Estudio de Evaluación Ambiental Estratégica que se realizó entre marzo y julio del 2011 por encargo del SERNAP (Servicio Nacional de Áreas Protegidasperteneciente al Vice ministerio de biodiversidad) ${ }^{5}$, en el TIPNIS es posible identificar dos lógicas o modelos de desarrollo que expresan visiones indígenas distintas y se vinculan de manera diferente con las propuestas de desarrollo que impulsa el gobierno boliviano de Evo Morales. Por un lado, una lógica económica que tiene sus bases materiales en la economía étnica amazónica de las comunidades indígenas yuracares, chimanes y moxeño trinitarias y que se desenvuelve en base a un eje: el uso, acceso y aprovechamiento de los bienes del bosque de forma colectiva. Ciertamente, la economía étnica de las comunidades indígenas opera bajo una esfera de economía de subsistencia donde se amalgama otra esfera de economía comunitaria que tiene que ver con el aprovechamiento sostenible de los bienes del bosque con fines de vinculación comercial. Por otro lado, una lógica económica que tiene bases materiales en la economía de producción de hoja de coca que es impulsada por los colonizadores andinos, quechuas y aymaras, quienes migraron a la región como fruto del programa de ocupación a tierras bajas del Estado nacional populista pos 52 y que se desenvuelve en base al eje de: uso, acceso y aprovechamiento de los bienes del bosque en forma individual. Este modelo económico prioriza en el contexto bosque un bien mayor: la tierra. Bosque convertible en tierra cultivable para la hoja de coca. Su producción tiene un destino exclusivamente comercial, la venta de hoja de coca.

Detallemos lo que significa el modelo de desarrollo que se desenvuelve en el seno de las comunidades indígenas amazónicas. $\mathrm{La}$ economía étnica que forma la base productiva y reproductiva de las comunidades indígenas yuracares, chimanes y moxejo trinitarias tiene bases en actividades tradicionales de caza, pesca, recolección y agricultura. Los tres pueblos indígenas realizan las cuatro actividades con sus matices. Por ejemplo, las familias indígenas yuracares y chimanes desarrollan agricultura en la selva alta y se caracterizan por sostener una agricultura de carácter agroforestal; en cambio, los mojeño trinitarios han desarrollado

\footnotetext{
${ }^{5}$ El trabajo fue realizado por la consultora Rumbol - Sociedad y Naturaleza, y estuvo compuesto por un equipo de 10 especialistas más 7 miembros del equipo técnico indígena del TIPNIS.
} 
más destrezas agrícolas en la región de los bosques inundables, sin manejar demasiadas parcelas agroforestales pero incorporando las regiones de sabana a su sistema productivo. La economía étnica que caracteriza a estas comunidades muestra un acoplamiento muy estrecho a los ritmos biovegetativos de los tres ecosistemas existentes en el TIPNIS ${ }^{6}$. Dicho acoplamiento es optimizado por las familias indígenas bajo un sistema de aprovechamiento de recursos caracterizado por la concentración y dispersión poblacional; esto es, comunidades que concentran familias indígenas donde se desarrolla centralmente agricultura y actividades menores de cacería, recolección, pesca y dispersión poblacional de las familias indígenas en un área de influencia grande comunal e intercomunal para centrarse en actividades de cacería, recolección y pesca.

La economía étnica de la zona responde centralmente a las necesidades de reproducción de las familias indígenas, es un modelo económico que tiene como eje el garantizar la seguridad alimentaria de los pueblos, por eso muchos la reconocen como una economía de subsistencia. La gran condición para su existencia es que el bosque y sus bienes no sean parcelados ni individualizados. Las bases materiales de su reproducción como sistema económico están en que las áreas comunales e intercomunales a las que acceden las familias indígenas, son de propiedad colectiva, por tanto, su gestión es una gestión compartida entre las distintas comunidades. En el caso de la actividad agrícola, los sistemas agroforestales son de beneficio familiar y se traspasan de una generación a otra en base a lazos consanguíneos. Las familias indígenas respetan el trabajo incorporado en los sistemas agroforestales y por eso el acceso es familiar y consanguíneo. En cambio el resto de las actividades, la cacería, recolección y pesca, se desenvuelven en los bosques comunales e intercomunales del territorio. De ahí el carácter de su propiedad colectiva. Así, el modelo económico que se desenvuelve entre las comunidades indígenas ubica a los bienes del bosque en un sentido de articulación integral. La valoración combinada de los bienes del bosque nos hace ver que la selva alta es tan importante como las parcelas agrícolas, los árboles son tan importantes como la tierra; lo propio, los animales que habitan en el bosque son tan importantes como los frutos de la agricultura o los recursos acuáticos. En ese sentido, la economía étnica antes que responder

${ }^{6}$ En el TIPNIS existen tres grandes ecosistemas. El primero que es el Subandino o serranía con bosque, el segundo que es el Pie de Monte o selva alta y el tercero que es el ecosistema de Bosques y Sabanas Inundables. En los tres ecosistemas existen especies endémicas de un alto valor para la reproducción de la biodiversidad en flora y fauna. Ver: Evaluación Ambiental Estratégica, La Paz, SERNAP, 2011. 
a las necesidades del mercado responde a las necesidades de las familias indígenas.

Amalgamando con la economía étnica de las familias indígenas, existe una esfera económica que funciona en base a modelos productivos comunitarios y que tiene como fin usar y aprovechar los recursos naturales renovables con destino comercial. Es posible afirmar que estos proyectos de desarrollo comunitario han sido madurados en un dialogo y contrapunteo con los criterios de conservación que se ponen en juego en el TIPNIS como área protegida. El 2001, como parte de una acción concertada entre las organizaciones indígenas y el SERNAP, se inicia la recategorización del Parque Nacional, formulándose nuevas formas de gestionar el área protegida. Desde entonces el TIPNIS está re categorizado en tres zonas: $1^{\circ}$ zona núcleo de extrema protección y conservación de la biodiversidad, susceptible de usarse para fines de investigación e ingresos fortuitos de caza y recolección por parte de las familias indígenas, $2^{\circ}$ una zona de uso tradicional que permite el desenvolvimiento de la economía étnica y $3^{\circ}$ una zona de uso sostenible de recursos que permite proyectar los planes de desarrollo comunitario en base a planes de manejo a) forestal, b) de cuero de saurios, c) turismo ecológico y d)agroforestal con chocolate nativo. La zona de uso sostenible de recursos se ubica en los bosques de galería que acompañan los ríos Sécure, Isiboro e Ichoa y básicamente estamos hablando de las áreas donde se asientan las comunidades.

Los planes de desarrollo comunitario que se desenvuelven en la zona $3^{\text {o }}$ están traduciendo una visión que proyecta a las comunidades hacia relaciones mercantiles regionales y globales. En el caso forestal y de saurios los circuitos son regionales, en el caso de turismo ecológico y chocolate nativo los circuitos son nacionales y globales. Lo que interesa resaltar en esta dimensión de desarrollo comunitario e intercomunitario es que el acceso, uso y gestión de los bienes del bosque no han roto con la propiedad colectiva tan presente en la economía étnica, es decir, no han roto con el eje fundamental que caracteriza la relación de las poblaciones indígenas con el bosque. El segundo elemento que interesa resaltar en los planes de desarrollo comunitario es que la dimensión integral de los bienes del bosque forma parte de lo que se está entendiendo como aprovechamiento sostenible de recursos. Usar y aprovechar diversificadamente los bienes del bosque, potenciando sus características y acompañando el beneficio que dan a las comunidades indígenas con planes de manejo para los recursos en cuestión, forma parte de la necesidad de un

${ }^{7}$ Ver mapa 2 
desarrollo comunitario que no quiere distanciarse del valor global del bosque. En ese sentido, la re categorización del TIPNIS lleva un implícito: se requiere proteger la biodiversidad del área y las iniciativas de desarrollo no pueden ir en contraste a los objetivos planteados en el área protegida. El plan propuesto en el 2001 categóricamente menciona que no puede haber exploración y sísmica petrolera en la zona núcleo o zona $1^{\text {o }}$ (Plan Estratégico de Gestión, Trinidad, SERNAP, 2001). ${ }^{8}$

Ciertamente, los elementos anotados son los que interesa analizar a la luz de la política estatal que busca construir la carretera por el TIPNIS. La lógica de los modelos de desarrollo comunitario buscan precautelar por el bien mayor que es el bosque y su conservación. No obstante, aunque son modelos que vinculan a las familias indígenas con circuitos mercantiles, el esquema productivo basado en la gestión colectiva de los recursos permite a las comunidades indígenas desarrollar un control político sobre el territorio. Justamente, es el control político sobre el territorio lo que en opinión de las comunidades, se vería ampliamente afectado con la construcción de la carretera. Ésta atravesaría la zona núcleo poniendo en riesgo el potencial de biodiversidad que alberga, o como dicen las comunidades indígenas "poniendo en riesgo la zona de producción de vida para el territorio; en el corazón del TIPNIS se produce la lluvia, se

${ }^{8}$ Es importante aclarar que en el caso de los planes de manejo forestal son las comunidades las que manejan y controlan el aprovechamiento, según lo programado en el plan de manejo. En ese sentido es inapropiado hablar de concesiones forestales dentro el TIPNIS, lo que hay son contratos de venta de producto forestal con empresas madereras. Los planes de manejo forestal fueron aprobados por la ABT en los años de 2007-2009 y contaron con el apoyo del SERNAP-MAPZA. Para el caso de aprovechamiento de cuero de saurio los planes de manejo fueron aprobados entre el 2005-2007 bajo el apoyo institucional de SERNAP-MAPZA. En el caso del chocolate estamos hablando de la expansión y crecimiento de las prácticas agroforestales tan presentes en la economía étnica. Finalmente, en el caso del proyecto de ecoturismo Pesca Deportiva, estamos hablando de una iniciativa que se desenvuelve en el alto Sécure y que reporta una ganancia de 200 \$us para las comunidades por cada turista que entra a la zona. En el periodo que va de abril a octubre, ingresan aproximadamente 420 turistas, por lo que las comunidades obtienen una ganancia líquida de 84.000 \$us que es repartida entre las comunidades beneficiarias del proyecto. Quien conduce la iniciativa es una empresa Argentina que ha firmado un contrato de servicios de ecoturismo con miembros de la subcentral Sécure y asigna, además de los 200 \$us por turista que entra a la zona, una cifra de 60 \$us por cada turista que llega a la región para fortalecimiento organizativo de la subcentral Sécure y subcentral TIPNIS, siendo un total de 25200 \$us que son destinados a fortalecimiento organizativo. La ficha ambiental de dicho proyecto fue aprobada por el SERNAP el año 2009 (datos de campo EAE, abril/julio 2011). 
reproducen los animalitos y nuestros mejores árboles están ahí". La carretera atravesaría la zona núcleo, la partiría en dos y, peor aún, siendo una zona que no tiene asentamientos indígenas ya que éstos se encuentran ubicados en la zona de uso sostenible de recursos, quedaría desprovista de control y protección territorial que estuvo vigente hasta el presente gracias a su difícil accesibilidad.

¿Por qué la carretera propuesta por el gobierno de Evo Morales supone un debilitamiento del control político del territorio? Porque ella trae la colonización, trae al productor andino quechua y aymara, trae la producción de hoja de coca, trae la individualización y parcelación de los bienes del bosque. La experiencia que tienen las comunidades indígenas del TIPNIS en la zona sur (polígono 7) es justamente un debilitamiento constante y sistemático del control político territorial que tuvieron como indígenas y que se revierte a favor del productor de hoja de coca que migro a la zona. Mucho más ahora que, en palabras de los indígenas, tienen un presidente. El riesgo mayor es justamente que la carretera producirá la colonización y ocupación de la zona núcleo del TIPNIS (Pie de Monte), arrinconará a los poblados indígenas y la estructura de economía étnica que integra y articula los planes de desarrollo comunitario que precautelan el bosque como un bien mayor, quedarán en una condición de extrema vulnerabilidad. Como lo registró Sarela Paz en la investigación que desarrollo en el TIPNIS en 1989-1990 "Nosotros los yuracares y trinitarios somos hombres que vivimos en los ríos, hacemos nuestras comunidades cerca a las orillas. En cambio los quechuas siempre están donde hay camino: donde se acaba el camino, ahí se acaban los collas" (Santísima Trinidad-Comunidad moxeño trinitaria. Impresiones de don Silverio Muiba, 1991).

Pasemos a detallar el modelo de desarrollo que se desenvuelve en el seno de los poblados quechuas y aymaras que se encuentran asentados en la región sur del TIPNIS, en el polígono 7, como lo designó el INRA ${ }^{9}$. La

${ }^{9}$ La designación del polígono 7 es fruto del proceso de saneamiento y titulación del Instituto Nacional de Reforma Agraria (INRA). Si en 1990 el territorio indígena fue reconocido mediante un Decreto Supremo, en 1997 se entregó a las comunidades indígenas del TIPNIS un título ejecutorial provisional sujeto a saneamiento; esto es, sujeto a un procedimiento que resuelva la sobre posición de derechos. El 2009, el presidente Evo Morales les entregó el título ejecutorial definitivo pues la zona ya ha sido saneada. Toda la región sur del TIPNIS que fue invadida por la colonización de quechuas y aymaras para producir hoja de coca, fue titulada como propiedad de terceros, es decir, que no pertenecen a la Tierra Comunitaria de Origen (TCO). El INRA designó esta zona como polígono 7 para proceder al saneamiento y la entrega de títulos. 
presencia del actor social colonizador en territorios amazónicos tiene fuente de explicación en la política pública nacional populista pos 1952, como ya hemos explicado anteladamente ${ }^{10}$. Sectores quechuas y aymaras que se desenvolvieron como campesinos en el marco de un Estado nacional populista, migraron a la región de los yungas tropicales con el fin de ampliar y diversificar su economía. La iniciativa de los colonizadores andinos de ocupar tierras en los yungas tropicales consolidó su participación en el desarrollo del mercado interno en Bolivia a través de productos como frutas, arroz, café, chocolate y por supuesto, el producto privilegiado de los yungas: la hoja de coca. ¿Qué es la característica específica de los colonizadores quechuas y aymaras del TIPNIS respecto de otras zonas de yungas en Bolivia? O respecto de las zonas del Chapare? El factor fundamental a entender en la dinámica de la colonización de los productores de hoja de coca del TIPNIS es que sus procesos migratorios vienen de los años 1982-1985 y 1986-1989, procesos migratorios que sostienen una estrecha relación con las políticas de ajuste estructural y de desplazamiento del Estado nacionalista hacia un Estado con contenido mucho más neoliberal. Empobrecimiento extremo de la economía campesina en ciertas regiones de los Andes (Norte de Potosí) y relocalización de mineros, producen migraciones masivas a la región sur del TIPNIS. Pero, a diferencia de sus otros pares colonizadores de los yungas de La Paz, Ixiamas o Ivirgarzama en el propio Chapare, en el TIPNIS el sujeto migrante centra su actividad agrícola en la producción de hoja de coca. Los estudios desarrollados por Carlos Hoffman en el polígono 7 nos muestran que el $95 \%$ del ingreso de las familias proviene de la hoja de coca (1994). Estamos entonces ante una región mono productora de hoja de coca y que tempranamente fue identificada como Zona Roja por sus vínculos con el narcotráfico.

El modelo de desarrollo impulsado por los productores de hoja de coca de la zona sur del TIPNIS supone una dinámica muy fuerte de

${ }^{10}$ Sin embargo, la relación de quechuas y aymaras con los yungas tropicales tiene origen en el criterio espacial andino de ocupación de diversos pisos ecológicos. El mayor control de nichos ecológicos garantizaba el acceso a mayor diversidad de productos agrícolas. La región de los yungas o de los Andes orientales se caracterizó, en este esquema de ocupación territorial de los Andes, por ser un espacio destinado a la siembra de hoja de coca cuyo destino era sustancialmente el consumo tradicional que realizaba de ella la mano de obra en el mundo andino. Hoy en día, el destino es sustancialmente otro. Ver: John V. Murra, El mundo andino: población, medio ambiente y economía, Lima, IEPUniversidad Católica, 2009. 
apertura de la frontera agrícola que implica deforestación, áreas de bosque tropical que son rápidamente convertibles a parcelas de producción de hoja de coca. En aproximadamente 25 años de avance de la colonización dentro del TIPNIS, el Pie de Monte que se ubica entre el alto Isiboro y el alto Ichoa ha sido ocupado y transformado en áreas agrícolas y centros poblados muy dinámicos que se caracterizan por tener los servicios básicos (agua, luz, sistema de alcantarillado), colegios con bachillerato, antenas repetidoras, terminal de buses y un mundo social conectado a dinámicas globales. Poblados como Aroma, Icoya, Minera A, Villa San Gabriel se han convertido en áreas que tienen un formato más urbano que rural.

El centro de la transformación y de la diferencia como modelo de desarrollo debe identificarse en la característica productiva de las familias de colonizadores andinos y las motivaciones de su migración. José Blanes y Gonzalo Flores (1984) puntualizan en sus investigaciones sobre el Chapare que el campesino andino, quechua o aymara, busca en las nacientes colonias que va ocupar, un desplazamiento económico y social. De campesino se proyecta a desplazarse hacia productor agrícola; ello implica monetarizar, mercantilizar su economía, diversificarla de tal forma que su producción tenga como destino el mercado regional de las ciudades bolivianas, además de una circulación ampliada de la mano de obra campesina. En ese sentido, el uso, acceso y aprovechamiento de los bienes del bosque se desenvuelve en forma individual y se prioriza un bien específico, la tierra. Por eso es que cuando el INRA entro a sanear la propiedad de la tierra dentro el TIPNIS, en la región de los productores de hoja de coca otorgó títulos individuales a solicitud de la decisión que habían tomado las centrales sindicales de productores de hoja de coca que se encuentran dentro del área, demarcando, además, los límites de la línea roja que se constituyen en la frontera a no ser rebasada por la colonización, la frontera entre la colonización y la TCO.

Las dos variables de comportamiento económico: característica de la tenencia de los bienes del bosque y destino de la producción agrícola, hacen que en la zona sur del TIPNIS el modelo de desarrollo impulsado por los colonizadores-productores de hoja de coca, sea muy diferente del modelo que compromete a las comunidades indígenas y su formato de economía étnica. Vista en esa dimensión las diferentes dinámicas, es claro que el proyecto de carretera para el modelo de desarrollo que impulsan los productores de hoja de coca, se convierte en un proyecto altamente funcional para sus despegues económicos. La carretera potenciaría las dinámicas mercantiles que manejan las familias cocaleras, pero además la carretera supone también articular, vertebrar todo el eje de Pie de Monte que se encuentra seguidamente a la cordillera oriental de los Andes. 
Yungas tropicales de los Andes orientales bolivianos que están siendo ocupados por los colonizadores en sus distintas regiones ${ }^{11}$ y que de abrirse la carretera Villa Tunari - San Ignacio de Moxos, consolidaría una proyección de control político sobre el territorio por parte de los colonizadores andinos; colonizadores quechuas y aymaras que a diferencia de un pasado donde portaban el registro de control vertical de nichos ecológicos como estrategia andina territorial, hoy día han vinculado la estrategia de ocupar distintos pisos ecológicos como una estrategia de manejar distintos nichos económicos, distintos circuitos mercantiles. El resultado económico es por supuesto sustancialmente distinto a lo que acontecía con el control vertical de nichos ecológicos por parte de los ayllus andinos.

Podría y debería pensarse que los productores de hoja de coca han encontrado en la colonización al Chapare una respuesta, una salida a la pobreza estructural de la economía campesina en los Andes que el Estado boliviano no supo dar. Esto es muy cierto y debe sopesarse a la hora del análisis. No obstante lo mencionado, los resultados de una dinámica económica iniciada hace más de 30 años en Bolivia tiene distintos finales que también deben evaluarse. Los productores de hoja de coca del TIPNIS ya no pueden ser leídos como hace 30 años porque las transformaciones económicas de las que forman parte han cambiado su lugar de desventaja en la estructura social boliviana. Son campesinos productores que forman parte de un enclave económico global, la economía del narcotráfico. El haberse convertido en monoproductores de la hoja de coca en los años 80, los ha puesto en un circuito económico de comercialización que está más allá de las fronteras nacionales. Ya en los primeros años de la década del 90 la zona colonizada del TIPNIS fue declarada por la fuerza de lucha contra el narcotráfico como Zona Roja debido a que su monoproducto tenía un destino de comercialización ligado a las rutas del narcotráfico.

La situación de enclave económico que responde a los ritmos de mercado global, a corredores de comercialización de estupefacientes, no ha cambiado con los años. En el mes de noviembre del 2011 la fuerza de lucha contra el narcotráfico ha encontrado una megafabrica de producción de cocaína en el río Isiboro -localidad de Santa Rosa- que establece vínculos comerciales de la zona con los carteles colombianos. La

\footnotetext{
${ }^{11}$ Comenzando de la frontera con el Perú está Ixiamas-Tumupasa, San Buena VenturaRurrenabaque, Yucumo-San Borja. En esa ruta el TIPNIS es una frontera natural no abierta. Más al sur-este se encuentra Isinuta-Eterasama, Villa Tunari-Chimore, Ivirgarsama-Yapacani, todo ello para ingresar al norte integrado donde se ha consolidado la agroindustria de Santa Cruz.
} 
comercialización de hoja de coca que es derivada a circuitos de consumo no tradicional -acullico y uso medicinal-, significa una presión sobre nuevas áreas agrícolas, avance de la frontera agrícola en desmedro del bosque. En la cadena de eslabonamiento de los enclaves económicos del narcotráfico, los productores de hoja de coca son abastecedores de la materia prima, el meganegocio no está en sus manos pero al formar parte de su dinámica económica se convierten en actores locales que presionan y luchan por obtener tierra para parcelas agrícolas. En los primeros años de la década del 90, los productores de hoja de coca del TIPNIS manejaban entre 10 y 20 hectáreas de hoja de coca. El centro de acopio de hoja de coca de Isinuta era el más importante de todo el Chapare. Hoy día manejan una cantidad mucho menor y se ha establecido una estructura de control social por parte del sindicato cocalero que regula el acelerado crecimiento de las parcelas agrícolas en la región.

La estructura de control social es una respuesta política de los sindicatos cocaleros a un contexto nacional. Las centrales sindicales de productores de hoja de coca del TIPNIS forman parte de las bases de origen del presidente Evo Morales. El control social tiene que ver con un mensaje a la sociedad boliviana: es el intento de desprender al gobierno de Evo Morales del significante que le persigue como gobierno cocalero. Aún así, los procesos de avasallamiento y de crecimiento de la frontera agrícola para producir hoja de coca siguen siendo parte de la dinámica sur del TIPNIS. En 2009 surgió un nuevo conflicto en la frontera de la línea roja, familias de productores de hoja de coca no sindicalizadas, rebasaron los mojones fronterizos del polígono 7 a la altura del río Lojojouta e ingresaron a la TCO para habilitar nuevas parcelas de hoja de coca. Hoy día si visitamos la zona, al frente de la comunidad indígena de Mercedes del Lojojouta, encontraremos un letrero que dice "Coca o Muerte". Además, el crecimiento de la dinámica agrícola de la hoja de coca ha alcanzado a las comunidades indígenas que se encuentran en la frontera, conviviendo con la colonización. Aproximadamente 10 comunidades indígenas se encuentran dentro del polígono 7 y otras 9 comunidades indígenas reciben la influencia de la economía de hoja de coca, ya sea porque producen hoja de coca o porque cosechan hoja de coca para los colonizadores, siendo un total de 19 comunidades indígenas que han quedado influenciadas por la producción de hoja de coca. En total son 64 comunidades indígenas en el TIPNIS. Las familias indígenas que han empezado a desplazarse a la producción de hoja de coca, se encuentran 
sindicalizadas, son miembros de los sindicatos cocaleros ${ }^{12}$. Esas comunidades hoy día marchan para que se abrogue la Ley de Protección al TIPNIS (180) y se construya la carretera.

\section{El desarrollo visto desde la gestión de gobierno de Evo Morales}

¿Cómo se vinculan los modelos de desarrollo que se han puesto en juego dentro del TIPNIS con la política de desarrollo que impulsa el gobierno de Evo Morales? Si bien el gobierno de Evo Morales se desenvolvió en el contexto de la agenda de octubre ${ }^{13}$ marcada por los movimientos sociales, lo cual implicaba, además de una convocatoria a la Asamblea Constituyente, el desarrollo de un modelo económico que suponga la industrialización de los hidrocarburos; en los hechos el desencadenamiento del modelo económico que terminó empujando el gobierno boliviano fue más bien de profundizar la tendencia secular y hegemónica del Estado; esto es, incentivar y apostar por salidas económicas que se basan en un modelo extractivista primario exportador. Tal condición en la esfera de la economía tiene varias implicancias. No es que se nieguen otras formas de desarrollo, de hecho el plan de gobierno presentado el 2006 asume una visión plural en cuanto a las formas económicas que el Estado debe apoyar, sin embargo, priorizar como fuente central de producción de riqueza la explotación de los recursos naturales y comercializarlos en su condición de materia prima, implica centralizar la política de Estado alrededor de las iniciativas extractivas. Éstas se vuelven prioritarias y, en muchos casos, razones de Estado. Ciertamente, una estructuración de la política económica en los términos mencionados supone la subordinación de otros modelos de desarrollo, los cuales pueden desenvolverse y hasta recibir incentivo de la política pública, siempre y cuando no afecten los planes centrales de la política económica extractiva.

\footnotetext{
${ }^{12}$ La investigación de Sarela Paz realizada en el 2006 muestra que las familias indígenas de la zona de frontera se desplazan a la producción de hoja de coca por los beneficios económicos que ésta reporta, dejando de lado actividades forestales (aprovechamiento de madera) que les producen ingresos menores (SERNAP, 2006).

${ }^{13} \mathrm{La}$ agenda de octubre estuvo marcada por la movilización de movimientos sociales urbano/rurales en Bolivia, desde la Guerra del Agua en el año 2000 hasta la Guerra del Gas en el año 2003, las movilizaciones articularon una agenda política conocida como la agenda de octubre. Convocatoria a la Asamblea Constituyente, industrialización del gas, representación política sin el monopolio de los partidos, nacionalización de los rubros estratégicos en recursos naturales, fueron parte de las aspiraciones políticas que proponían los movimientos sociales.
} 
El conflicto del TIPNIS expresa exactamente un hecho de tal naturaleza: poblaciones indígenas que no están de acuerdo con los planes centrales de la política económica extractiva.

Dialogando con el debate de modelos económicos extractivos desarrollado en los últimos años en América del Sur, hoy como en un pasado, las bases y criterios de definición del modelo extractivo no se han modificado demasiado. Se trata de una forma de desarrollo económico que basa la producción de riqueza en la apropiación de la naturaleza, bajo un formato productivo escasamente diversificado, recursos naturales que no son procesados o lo son limitadamente y que de su venta depende la inserción del país productor de materias primas al mercado internacional. La similitud con el pasado nos muestra, sin embargo, algunos elementos nuevos que es necesario destacarlos. El más importante es que en el nuevo contexto el Estado juega un rol más protagónico, de intervención y definición de unas reglas de juego que permite una mejor redistribución de la riqueza. Como detallan los trabajos de Gudynas (2009) y Acosta (2011), la redistribución de la riqueza producida por las iniciativas extractivas en los gobierno progresistas como Bolivia y Ecuador, se desenvuelve mediante programas sociales de atención a poblaciones vulnerables, en muchos casos de gran pobreza y que se convierten en el mayor dispositivo de legitimación de los modelos económicos extractivos y de los gobiernos que los impulsan.

Los datos elocuentes de la CEPAL para el 2009 sobre exportación de bienes primarios en las economías extractivas sudamericanas, muestran la tendencia en países como Bolivia. En Sudamérica, sin ser la mejor situación, Colombia y Brasil muestran una tendencia de menor dependencia de las exportaciones de bienes primarios, en cambio, Venezuela, Bolivia y Ecuador muestran una casi total dependencia de la exportación de bienes primarios respecto de las exportaciones totales de estos países. La exportación de bienes primarios como hidrocarburos y minerales en Venezuela alcanzan al $92.7 \%$ de las exportaciones que se dan en dicho país. En el caso de Bolivia la cifra asciende a $91.9 \%$ y en el caso de Ecuador el porcentaje es de 91.3\% (GUDYNAS, 2009 con base a los datos de la CEPAL). Según el estudio de Christian Ferreyra, en Bolivia entre el 2004 y el 2007 se ha desarrollado un incremento sostenido de la minería pero entre el 2007 y el 2009 podemos detectar un gran salto en las exportaciones mineras de 1.222.984 millones de bolivianos a 2.100.161 millones de bolivianos. El mismo estudio nos muestra que en el caso del gas la producción entre los años 2000 y 2005 pasó de 8.8 MMmcd. a 33.3 
MMmcd. y entre el 2006 y el 2008 la producción de gas natural aumentó a 38.7 MMmcd (2011: 11-12) ${ }^{14}$.

Podríamos alegar que el crecimiento en las exportaciones de materia prima demuestra no solo la profundización del modelo extractivo y la ineludible importancia del extractivismo minero e hidrocarburífero en la estructura económica boliviana, sino también las nuevas oportunidades del Estado boliviano para obtener mayores ganancias y lograr inversiones en posibles procesos de industrialización, como plantearon los movimientos sociales en la agenda de octubre. No obstante ello, la tendencia muestra que no hay esfuerzos concretos que caminen en un nuevo tipo de desarrollo, la dependencia del gasto público que proviene de la renta hidrocarburífera se ha ahondado en los últimos años, así como, se han generado condiciones más favorables para la intervención de la Inversión Extranjera Directa en el sector extractivo (Fundación Milenio, 2010). También la base y fundamento de la nacionalización en hidrocarburos muestra sus límites. Si con el Decreto de Nacionalización de mayo del 2006 se aplicó al criterio de renta petrolera que alcanzaba a 50\%, un 32\% más aplicable a los megacampos de producción de gas, para con ello crear un fondo de capital que permita el desarrollo de la industria petrolera nacional, el 2007, al protocolizar los nuevos contratos con las empresas petroleras, se quitó este $32 \%$ volviendo a la situación inicial de antes de la nacionalización (FERNÁNDEZ, 2011: 131).

Las políticas del gobierno de Evo Morales muestran mayor interés por abrir nuevas áreas de exploración y explotación hidrocarburífera (gas y petróleo) antes que generar políticas que permitan el desarrollo de una industria energética en Bolivia. Seguramente, de manera similar razonan las transnacionales petroleras que operan en Bolivia. Desde la aprobación de la Ley de Hidrocarburos $\mathrm{N}^{\mathrm{0}} 3058$ en mayo del $2005^{15}$, el gobierno de Evo Morales ha ampliado el número de áreas de interés hidrocarburífero destinadas a favor de Yacimientos Petrolíferos Fiscales Bolivianos (YPFB). Lo que interesa resaltar en dicha política no es, por supuesto, que YPFB tenga más áreas de aprovechamiento hidrocarburífero, sino que

\footnotetext{
${ }^{14}$ En la segundo semana del mes de marzo del 2012, el presidente Evo Morales ha anunciado que la producción de gas en Bolivia deberá llegar a la cifra de 50.0 MMmcd hasta el 2015.

${ }^{15}$ La Ley de Hidrocarburos $\mathrm{N}^{\circ} 3058$ fue aprobada el 17 de mayo del 2005 durante la gestión de gobierno de Carlos de Mesa. La nacionalización de los hidrocarburos en Bolivia, realizada por el gobierno de Evo Morales, no implicó modificación de la mencionada ley. Por tanto, en Bolivia está vigente una ley de hidrocarburos que fue promulgada antes de que Evo Morales llegue a la presidencia.
} 
dichas áreas tradicionales y no tradicionales han empezado a implicar a las áreas protegidas y territorios indígenas; además que dichas áreas que empiezan a ser destinadas a la exploración y explotación de hidrocarburos, están siendo concesionadas a YPFB pero bajo la figura de sociedad mixta con empresas transnacionales. Por tanto, no son áreas de operación exclusiva de la empresa petrolera boliviana.

Basándose en el artículo 34 de la Ley de Hidrocarburos No 3058 aprobada el año 2005, el gobierno de Evo Morales mediante Decreto Supremo $\mathrm{N}^{\circ} 29130$ de mayo del 2007, propone reservar 21 áreas tradicionales y no tradicionales de interés hidrocarburífero a favor de YPFB y, en el mismo año, mediante Decreto Supremo No 29226 promulgado en el mes de agosto, el gobierno de Morales modifica las áreas de interés hidrocarburíferas a favor de YPFB en un número de 33 Bloques que son susceptibles de ser aprovechados bajo la figura de sociedad mixta. Tres años después, en octubre del 2010, el gobierno de Evo Morales promulga el Decreto Supremo N $^{\circ} 676$ donde no solo se amplían las áreas de interés hidrocarburíferas a favor de YPFB en un número de 56 sino que se propone de manera directa permitir excepcionalmente actividades hidrocarburíferas en áreas protegidas, postulando en el parágrafo II del art. 2 del mencionado Decreto que las áreas reservadas a favor de YPFB, si se encuentran en áreas protegidas, se deberá garantizar el cumplimiento de emplear adecuadas tecnologías que permitan mitigar los daños socioambientales y culturales. En el Decreto Supremo No 29130 de mayo 2007 encontramos el Bloque Sécure 19 y 20 como área no tradicional de interés hidrocarburífero reservado para YPFB.

En razón de lo mencionado, el gobierno de Evo Morales tiene una política de desarrollo económico que prioriza los modelos extractivos energéticos, convirtiéndolos en política de Estado, en el eje económico de la política pública. Para el caso concreto del TIPNIS el gobierno de Evo Morales ha otorgado dos concesiones petroleras para exploración y explotación, desconociendo la normativa ambiental que hay en áreas protegidas y violando la decisión construida por miembros del SERNAP y las organizaciones indígenas el año 2001 cuando se re categoriza el TIPNIS y se menciona que no podrá haber actividad petrolera en el territorio indígena y área protegida (Plan Estratégico de Gestión, Trinidad, SERNAP, 2001). Dos concesiones han sido otorgadas: la primera mediante la Ley $\mathrm{N}^{\mathrm{o}} 3672$ de abril del 2007 que aprueba el Contrato de Operaciones entre Yacimientos Petrolíferos Fiscales Bolivianos (YPFB) con PETROBRAS BOLIVIA S. A. y la TOTAL E\&P BOLIVIE en el área de Río Hondo (bloque Ichoa) y la segunda mediante Ley $\mathrm{N}^{\mathrm{o}} 3911$ de abril del 2008 con su adendum en julio del mismo año que aprueba el contrato 
de exploración y explotación entre Yacimientos Petrolíferos Fiscales Bolivianos (YPFB) y YPFB PETROANDINA S.A.M. (Evaluación Ambiental Estratégica-SERNAP 2011) ${ }^{16}$. Roberto Fernández (2011) nos hace ver en su estudio sobre los hidrocarburos en Bolivia que la gestión de gobierno de Evo Morales se está acercando a la máxima de "exportar o morir" y por ello está urgido de abrir nuevos bloques a la explotación hidrocarburífera. Es claro que el tramo carretero Villa Tunari San Ignacio de Moxos brindará condiciones para las operaciones petroleras de ambas concesiones. En la comprensión del negocio de hidrocarburos que manejan las transnacionales, las carreteras son ítems de inversión del Estado.

Construir infraestructura para que los modelos extractivo exportadores operen con costos relativamente razonables, forma parte de la lógica de gobiernos y Estados ampliamente comprometidos con los modelos primario exportadores. $\mathrm{Y}$ cuando se piensa en los modelos extractivos, no solo debemos referirnos a los que extraen materias primas sino también forman parte de ello, según la propuesta de Gudynas (2009), los modelos agroexportadores que funcionan en base al mono cultivo y la expoliación extrema de la tierra. Proyectando el razonamiento a una dinámica más regional, los circuitos comerciales que garantizan la circulación de bienes primarios entre los que se suman los producidos por la agroindustria, deben ser consolidados en función al mercado global. Los retos no son menores, la década que iniciamos supone una relación muy dinámica de los productos que ofrece América del Sur hacia los mercados de la China. La creciente demanda de productos mineralógicos que tiene dicho país, hace que América del Sur se convierta en un lugar de presiones estratégicas y que el plan de iniciativa para la Integración de la Infraestructura Regional Sudamericana (IIRSA) cobre más sentido en función a la comunicación interoceánica que producirá.

Según Mónica Bruckmann desde 1990 la China se ha convertido en un país que produce y demanda gran cantidad de minerales. En la última década la China se ha convertido en el principal productor de un número importante de minerales, aún así, no logra cubrir su demanda interna, registrando cifras muy altas de importación en cobre, hierro y otros minerales. La información organizada por la investigación de Bruckmann nos muestra que en la China el horizonte intensivo de consumo de mineral

\footnotetext{
${ }^{16}$ Ver mapa $3^{\circ}$ sobre concesiones petroleras en el TIPNIS. Importante resulta señalar que las concesiones petroleras se ubican sobre todo en el Subandino del territorio indígena área protegida, comprometiendo la zona núcleo del TIPNIS. También aclarar que PETROANDINA es un consorcio entre YPFB y PDVSA.
} 
para consolidar su industria ligera, se proyecta 20 años más y que desde el 2000 la manufactura pesada de dicho país crece sistemáticamente. El primer destino de las exportaciones mineras de Chile y Brasil va hacia la China, el segundo destino de las exportaciones mineras de Perú y Argentina va hacia la China y el primer producto de exportación de Bolivia hacia la China es estaño (2011). En ese contexto, ¿cuál será el destino de productos agroindustriales que se están desenvolviendo en América del Sur?. El circuito comercial a consolidarse muestra desplazamientos de materia prima como mineral y agroproductos como la soya hacia los mercados de la China y el Asia ${ }^{1 f}$. En otro sentido, la industria manufacturada de estas regiones observa con buenos ojos conquistar plenamente el mercado de Sudamérica. Este es el contexto donde la comunicación interoceánica potenciada por el plan de iniciativa para la Integración de la Infraestructura Regional Sudamericana (IIRSA), alza vuelo y despliega sus raíces en función de procesos productivos basados en modelos extractivos.

El reto fundamental de la comunicación interoceánica es justamente atravesar la cordillera de los Andes y para países como Brasil que se ubican plenamente en el Atlántico, resulta hasta estratégico la consolidación de infraestructura caminera que atraviese los Andes. Atravesar los Andes desde el Atlántico, es para un país como el Brasil, atravesar los Andes desde la Amazonía, para lo cual las regiones de selva alta o las regiones de selvas tropicales tienen una doble importancia: $1^{\circ}$ geográficamente se rompen fronteras naturales poco asequibles hace 30 años, $2^{\circ}$ son regiones que contienen energía fósil. Atravesar con caminos la región de los yungas orientales implica no sólo comunicación interoceánica sino también la posibilidad de obtener energía fósil de la formación Subandina. Este es un proyecto apetecido por Petrobras y, en el horizonte inmediato, países como Perú y Bolivia, adquieren su importancia específica puesto que ambos poseen dos patas en el modelo extractivo primario exportador, minería e hidrocarburos, siendo el rubro petróleo el que puede adquirir un mayor desarrollo en la faja Subandina de estos

${ }^{17}$ Los principales productos de exportación de los países de América del Sur hacia la China, claramente se marcan en el rubro de minerales y soya. El primer producto de exportación de Brasil a China es hierro, el segundo producto es soya. En el caso de Argentina el primer producto de exportación a China es soya. Para el caso de Bolivia el primer producto de exportación a China es estaño. Chile tiene al cobre como primer producto de exportación a China y para Uruguay el primer producto de exportación a China es la soya (BRUCKAMANN 2011). 
países, a diferencia de Ecuador que posee iniciativas petroleras ampliamente desarrolladas en la faja Subandina.

La carretera Villa Tunari San Ignacio de Moxos y su importancia estratégica en la región debe entenderse en el contexto arriba mencionado, forma parte de la iniciativa de romper con las fronteras naturales de la selva alta que nos dan acceso a los Andes y luego al Pacífico, pero también forma parte de la faja Subandina donde podemos obtener energía fósil. No por nada las concesiones petroleras a Petroandina y Petrobras. Para el Brasil y sus proyectos energéticos hasta el 2020 donde corre el riesgo de tener un déficit de energía, nuevos campos de exploración petrolera resultan atractivos, mucho más si éstos poseen la infraestructura necesaria para operaciones de exploración y explotación. La comunicación interoceánica sirve también para el creciente desarrollo de la agroindustria que se está desencadenando en estados como Acre, Rondonia o Mato Grosso do Norte, estados frontera con Bolivia y Perú que ven en la vinculación caminera que atraviesa los yungas orientales una oportunidad para bajar costos de operación llegando hacia el Pacífico con sus productos. Ciertamente, en el escenario de los modelos extractivos primario exportadores, no todos los países estamos en las mismas condiciones. Aunque como lo demuestran los estudios de Gudynas (2009), Acosta (2011), Svampa (2009), Verdum (2010), América del Sur está consolidando su condición secular de seguir siendo abastecedora de materias primas al mercado global, internamente hay países como Bolivia que tienen una pequeña estructura industrial respecto de países como Brasil que combinan su estructura primario exportadora con una considerable estructura industrial que favorece a un posicionamiento geopolítico en el flujo de relaciones de modelos extractivos primario exportadores ${ }^{18}$. La condición geopolítica del Brasil permite entender porque BNDES que es un consorcio público/privado que actúa en infraestructura y extracción, es la entidad que otorga el crédito para la carretera y OAS una empresa brasilera que se adjudica la construcción.

Volviendo a nuestra pregunta inicial ¿cómo se vinculan los modelos de desarrollo que se han puesto en juego dentro del TIPNIS con la política de desarrollo del gobierno de Evo Morales y la dinámica económica regional que plantea varios retos geopolíticos en cuanto al desarrollo económico para América del Sur? Es claro que el modelo indígena basado

\footnotetext{
18 Según Ricardo Verdum, en América del Sur Brasil es un país que tiene una política clara para el sector industrial, le sigue Argentina y por detrás Uruguay. Chile en cambio, en su canasta de productos de exportación se parece a Perú y Bolivia con más del $70 \%$ de sus exportaciones comprometidas en el rubro de la minería (VERDUM, 2010).
} 
en una economía étnica amazónica y amalgamado a un uso y aprovechamiento sostenible de los recursos expresado en los planes de manejo que impulsaron los indígenas y miembros del SERNAP, entra en coalición con las propuestas de desarrollo del gobierno de Evo Morales. Éste se vuelve cada vez más dependiente en sus ingresos fiscales de los rubros primario exportadores en minería e hidrocarburos y, a la vez, vuelve más dependiente de dichos ingresos los programas sociales que viene llevando a cabo ${ }^{19}$. La segunda gestión del presidente Evo Morales marca claramente el desplazamiento en la política económica, las iniciativas extractivas primario exportadoras se han vuelto razones de Estado, nadie las puede discutir y menos interrumpir en su desenvolvimiento. Los indígenas del TIPNIS al oponerse que la carretera Villa Tunari San Ignacio de Moxos pase por el área núcleo del territorio y parta en dos el área protegida, básicamente se han opuesto a los planes de política extractivista que tiene el gobierno y a los planes de creación de infraestructura que reducen costos y tiempo a los modelos extractivos primario exportadores. En ese contexto, los modelos de desarrollo comunitario de los indígenas del TIPNIS se han convertido en propuestas que son perseguidas políticamente. Se han suspendido los proyectos de ecoturismo, forestales y de aprovechamiento de cuero de saurios a título de que el TIPNIS es intangible; sin embargo, las iniciativas de los productores de hoja de coca dentro del TIPNIS no han sido tocadas.

Con sustancial diferencia, el modelo de desarrollo de los productores de hoja de coca engrana con las dinámicas extractivas primario exportadoras. De hecho como enclave productor de materia prima para el negocio regional de cocaína, reproduce una buena parte de las características que tiene el negocio de la agroindustria que ha sido tipificado como parte de los modelos extractivos. Primero, es monoproductor del bien a exportarse (hoja de coca-pasta base), segundo, usa intensivamente la tierra en desmedro del bosque, causando daños irreversibles para la composición biovegetativa de la zona sur del TIPNIS, tercero, produce el bien agrícola (hoja de coca) en función exclusiva a las necesidades del mercado global. La única gran diferencia con los modelos extractivos agroindustriales es que la mono producción no está en manos de empresarios que controlan la tierra y el proceso productivo sino más bien en manos de campesinos que buscan optimizar la producción de hoja

${ }^{19}$ Bono Juancito Pinto que es para los estudiantes de la escuela pública en ciclo básico, bono Juana Azurduy de Padilla para las mujeres en estado de gestación y lactancia, Renta Dignidad para las personas de tercera edad en el campo y la ciudad, forman parte de los programas sociales que son financiados con la renta hidrocarburífera. 
de coca abriendo cada año nuevas fronteras agrícolas. Para ello, un tramo carretero resulta estratégico en la ampliación de nuevas fronteras agrícolas $\mathrm{y}$, por el comportamiento de los poblados de colonos en la zona, la saturación de las áreas agrícolas con cultivo de hoja de coca está empezando a pronunciarse. En ese contexto, el avasallamiento a nuevas áreas agrícolas sobre el bosque de la TCO del TIPNIS se muestra como una estrategia útil y necesaria para la dinámica de producción y comercialización de la materia prima de la cocaína. Un esquema productivo de tal naturaleza puede convivir con relativa sintonía con la exploración y explotación petrolera.

\section{Lanzando algunas conclusiones}

Las situaciones de contradicción/constatación que nos muestra el conflicto del TIPNIS nos debe llevar a analizar algunos elementos críticos que está viviendo el proceso boliviano. El primer elemento a considerarse es que los pueblos indígenas en Bolivia no necesariamente comparten la misma visión de desarrollo, la misma comprensión acerca de lo que significa "vivir bien" $\mathrm{y}$, además, no necesariamente los indígenas se distancian social y económicamente de un modelo extractivo primario exportador. El caso del TIPNIS en Bolivia muestra con mucha claridad que los pueblos indígenas portan miradas de desarrollo que son producto de sus procesos histórico estructurales y no así, como lecturas primordialistas lo quieren ver, producto de comprensiones esenciales en el ser indígena. Los pueblos amazónicos en Bolivia han vivido procesos económicos muy distintos de los pueblos quechuas y aymaras, y si bien ambos comparten la experiencia estructural de haber sido colonizados y subalternizados en la dinámica del Estado colonial republicano, lo cierto es que las distintas iniciativas de desarrollo que están empujando dentro del TIPNIS obedece a sus distintos nexos con los circuitos de capital global. Básicamente, la proyección de la política étnica en Bolivia ha encontrado su límite en la proyección de la política económica estructural. Para entender la problemática, por tanto, necesitamos integrar en el análisis las dos variables.

En ese contexto, el Estado vuelve a una condición inicial en el análisis estructural; esto es, no es una institución que está por encima de las clases y los sectores sociales, más bien expresa las luchas internas de las clases y los sectores sociales. En el conflicto del TIPNIS el Estado, 
mediado por el gobierno de Evo Morales, expresa un posicionamiento que refleja la composición de poder dentro de las nuevas lógicas del Estado boliviano. No es casualidad que los productores de hoja de coca hayan logrado un presidente, es más bien una estrategia de poder construida a lo largo de varios años y que refleja los cambios sociales y económicos que se han venido gestando hace más de 30 años en el conglomerado quechua y aymara que colonizó el TIPNIS. Los sujetos andinos colonizadores de los años 1960, 1970, 1980, hoy en día se ubican en un espacio distinto en la estructura social boliviana. En otras palabras, detrás del conflicto del TIPNIS hay procesos orgánicos de recomposición de clases en Bolivia y los modelos extractivos primario exportadores que se desenvuelven con características seculares en su matriz económica, están intentando reacomodarse en la sísmica social que se viene produciendo en Bolivia.

Esa sísmica social en Bolivia nos muestra que, entre los programas estatales orientados por modelos extractivistas primario exportadores y sectores sociales no tradicionales de la estructura económica boliviana, pueden desarrollarse complicidades que permiten el despegue de ambos, necesarios para el desarrollo del capital, y muy necesarios en sociedades donde la estructura social y económica estuvo profundamente anclada en élites y oligarquías que portan visiones pasadas de la economía y la sociedad. Es muy probable que situaciones similares se estén desarrollando en un país como Brasil donde sectores convencionales de fazendeiros en estados como Rondonia o Acre, se convierten en una traba al flujo de circuitos sociales y económicos que permiten una circulación más ampliada del capital. Visto desde otra perspectiva, los modelos extractivos primario exportadores se están desarrollando, en países como Bolivia, en un contexto de procesos de movimiento y democratización de la estructura social boliviana que terminará cambiando la composición de clases sociales y su relación con el movimiento de capital global. En ese sentido, las características del extractivismo y/o el neo extractivismo de América del Sur tienen que analizarse más allá de la política de redistribución de riquezas que caracteriza a los gobiernos progresistas, porque pueden estar produciendo una estructuración social distinta a la conocida y manejada por la matriz inicial.

El desafío más grande que nos ha puesto el conflicto del TIPNIS en Bolivia es, sin embargo, el referido a la posibilidad de que la forma política del Estado Plurinacional pueda albergar modos y procedimientos del modelo extractivo primario exportador, sin caer en una agotadora contradicción que la puede destinar a su propio destierro. El modus operandis de las iniciativas extractivas requiere no solo de un Estado fuerte sino de un Estado mono nacionalista, o por lo menos, así han operado 
dichas iniciativas por varios siglos. La condición de plurinacionalidad puede convertirse en su talón de Aquiles puesto que implica discutir decisiones que desde el mono nacionalismo son tratadas como: "asuntos de bien común", "asuntos de Estado", "decisiones que no se discuten". En ese sentido, tanto en Bolivia como Ecuador que son países altamente dependientes de estructuras económicas basadas en modelos extractivos primario exportadores, se está restituyendo a una velocidad no esperada modos y prácticas de nacionalismos pasados, con retoricas nuevas como "movimiento ciudadano" o "movimiento indígena" pero que finalmente anclan formas y maneras de decidir la política pública sobre economía, como en las décadas pasadas del siglo XX. La plurinacionalidad en ambos países no es producto de la magia que pudo haberse producido en el proceso constituyente, es fruto de razonamientos políticos de sus movimientos sociales marcadamente indígenas en ambos países. En ese sentido, el potencial conflicto que se proyecta en ambos países, puede ser altamente crítico, sobre todo cuando sectores del movimiento indígena, como aconteció en Bolivia, no están dispuestos a negociar su condición de plurinacionalidad que implica básicamente no negociar su derecho a la libre determinación. 
MAPA 1. PROYECTO DE CARRETERA 1 Y 4 COCHABAMBA VILLA TUNARI PUERTO VILLARROEL Y VILLA TUNARI RÍO ISIBORO PLANIFICADO POR EL GOBIERNO BOLIVIANO Y APOYADO POR U.S. AGENCY FR INTERNATIONAL DEVELOPMENT (USAID) - 1966

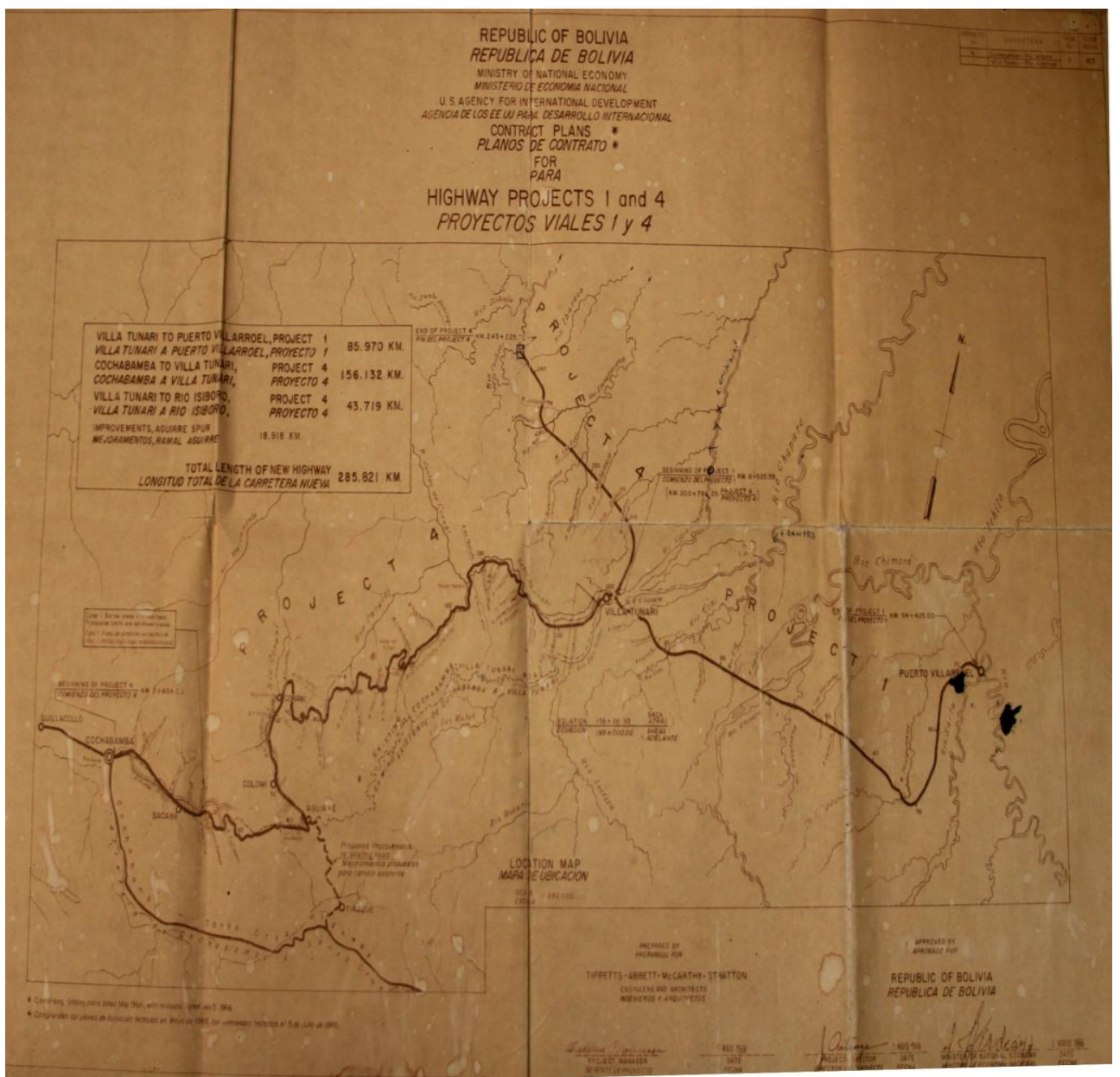


MAPA 2. ZONIFICACIÓN DEL TIPNIS TRABAJADA POR EL SERNAP Y LA SUBCENTRAL INDÍGENA TIPNIS EN EL AÑO 2001

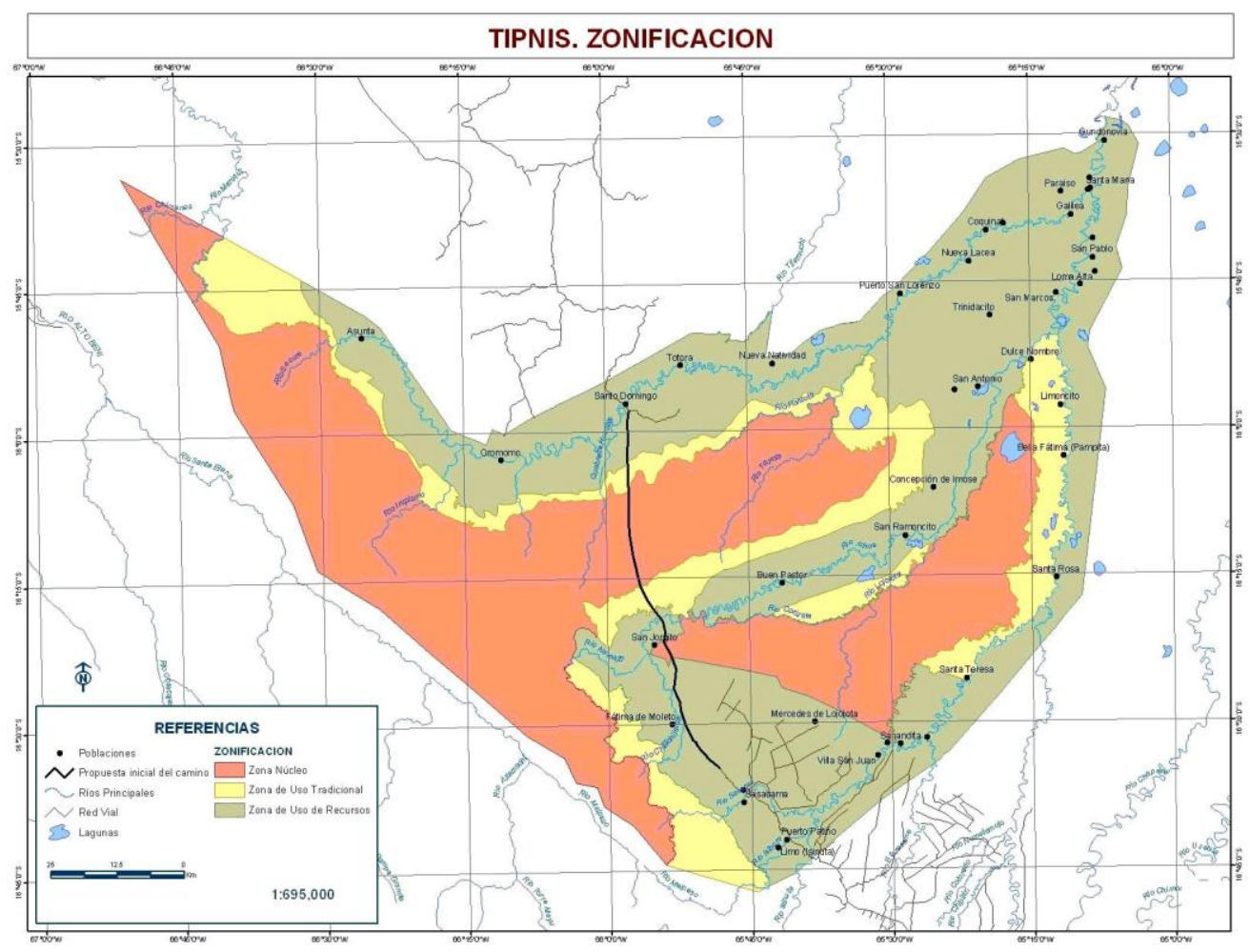


MAPA 3. CONCESIONES PETROLERAS OTORGADAS POR EL GOBIERNO DE EVO MORALES EN LOS AÑOS DE 2007 Y 2008 A PETROBRAS Y PETROANDINA QUE COMPROMETEN EN GRAN PARTE EL ÁREA NÚCLEO DEL TIPNIS

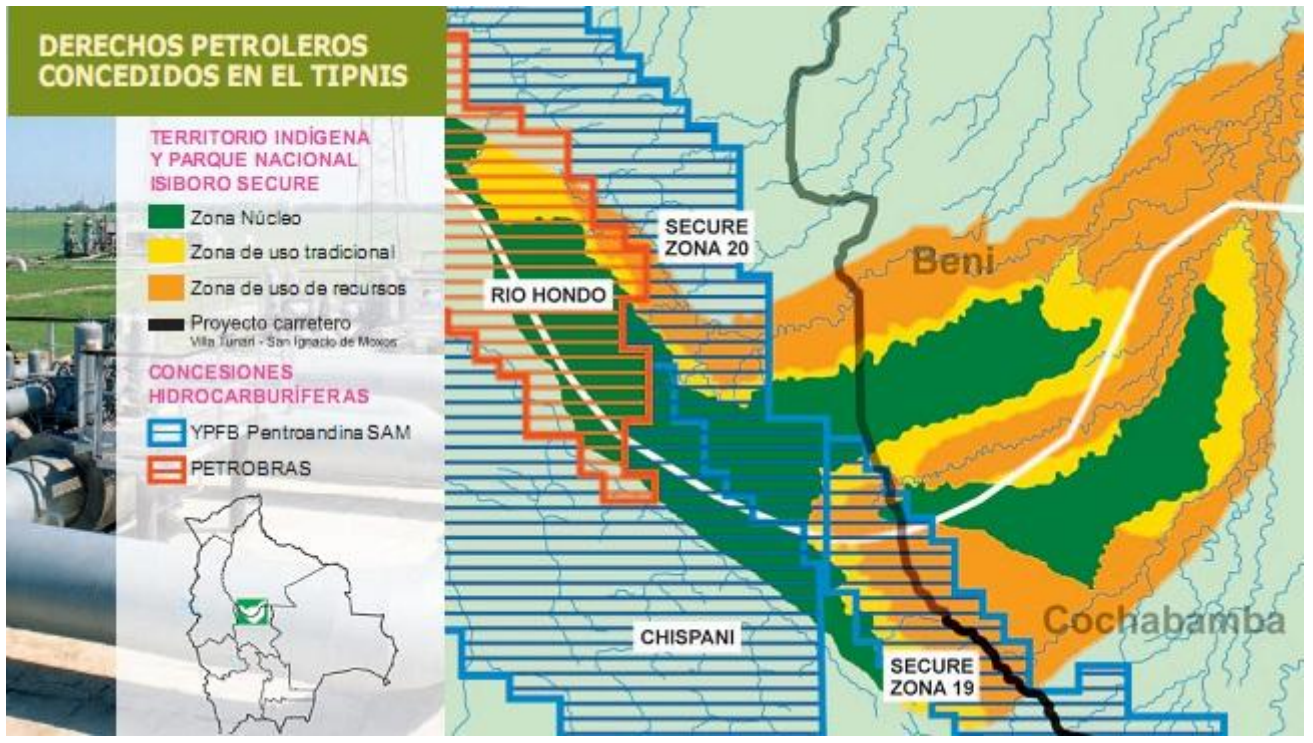




\section{LA MARCHA INDIGENA DEL “TIPNIS" EN BOLIVIA Y SU RELACIÓN CON LOS MODELOS EXTRACTIVOS DE AMERICA DEL SUR}

Resumo: O artigo analisa as contradições e os conflitos entre o modelo de desenvolvimento comunitário proposto pelos grupos indígenas no TIPNIS (Território Indígena e Parque Nacional Isiboro-Sécure) e o modelo extrativo primário exportador presente no Estado boliviano.

Palavras-Chave: TIPNIS, Bolívia, Estado boliviano, Indígenas, Modelos Extrativos

INDIAN'S PROGRESS "TIPNIS" IN BOLIVIA AND ITS RELATIONSHIP WITH MODELS OF SOUTH AMERICA EXTRACTIVE

Abstract: This article analyses contradictions and conflicts between the communitarian development model proposed by Indian groups from TIPNIS (Isiboro-Sécure Indian Territory and National Park) and the primary-extrative export model of Bolivian State.

Keywords: TIPNIS, Bolivia, Bolivian State, Indians, Extrative Models

\section{BIBLIOGRAFIA}

ACOSTA, A. (2011). Extractivismo y neo extractivismo: dos caras de la misma maldición. Quito: Línea de Fuego.

BLANES, José y Flores, GONZALO (1984). ¿A dónde va el Chapare? Cochabamba: CERES.

BRUCKMANN, M. (2011). Recursos naturales y la geopolítica de la integración Sudamericana, Proyecto Governança Global e Integração da América do Sul. Brasilia: Instituto de Pesquisa Económica Aplicada.

Consultora Rumbol (2011). Evaluación Ambiental Estratégica del TIPNIS. La Paz: SERNAP.

FERNÁNDEZ, R. (2011). "El reacomodo del poder petrolero transnacional en Bolivia". In: La mascarada del poder: respuestas a Álvaro García Linera. Varios autores. Cochabamba: Escuela del Pueblo $1^{\circ}$ de Mayo.

FERREYRA, C. (2011). "El neo-extractivismo en tiempos de cambio. Desarrollo de los sectores extractivos y problemática ambiental". In: 
Impactos ambientales y recursos hídricos, Rev. Agua y Ambiente, n. 5, Cochabamba, marzo, p. 7-26.

Fundación Milenio (2010). Informe de Milenio sobre la economía. Gestión 2009, n. 28, La Paz, abril.

GUDYNAS, E. (2009). "Diez tesis urgentes sobre el nuevo extractivismo: contextos y demandas bajo el progresismo sudamericano actual". In: Extractivismo, Política y Sociedad. Diversos autores. Quito: CAAP y CLAES y Fundación Rosa Luxemburgo. p. 187-225.

HOFFMAN, C. (1994). Diagnóstico socioeconómico / Área Colonizada del Parque Nacional Isiboro Sécure. Cochabamba: Unidad del Trópico.

LASERNA, R. (1987). Sociedad Regional. Cochabamba: CERES.

Murra, Jhon (2009). El mundo andino: población, medio ambiente y economía. Lima: IEP-Universidad Católica.

PAZ, S. (1991). Hombres de río, hombres de camino: relaciones interétnicas en las nacientes del río Mamoré. Cochabamba: Universidad Mayor de San Simón.

(2006). Marco comprensivo para avanzar en la Línea Base de las comunidades indígenas del Bloque I Isiboro. La Paz: SERNAP.

(2012). "El conflicto del Territorio Indígena Parque Nacional Isiboro Sécure (TIPNIS): sus consecuencias para el Estado Plurinacional de Bolivia". In: Estado Plurinacional: balances y perspectivas. La Paz: PNUD-Embajada de Suecia. Boletín 3 y 4, enero.

SORUCO, X. 2008. Los Barones del Oriente. La Paz: Fundación Tierra.

SVAMPA, M y M.A. ANTONELI, (ed.) (2009). Minería transnacional, narrativas del desarrollo y resistencias sociales. Buenos Aires: Biblios.

VERDUM, R. (2010). El nuevo extractivismo desarrollista en Sudamérica, Washington, DC: Center for International Policy, Programa de las Américas Reporte, enero. 